always been notable for its generous provision of illustrations, and students appreciate the way in which so much of the experimental material is presented graphically so that it can be more quickly grasped and more easily remembered. The experimental evidence for the facts is given so far as possible, and this is one of the most valuable qualities of the book.

I was disappointed not to find any diseussion of the interesting genetic and biochemical features of abnormal hæmoglobins such as the one associated with sickle cell anæmia, nor anything about the trial of diets low in phenylalanine as a possible means of preventing brain damage in infants suffering from phenylketonuria. In a book used so much by medical students some of the over-generous space given up to structural formulæ of, say, the porphyrins might be better used in some such way. This is not a plea for a larger volume: indeed, the authors are to be congratulated on having made this edition slightly smaller than the one before-something that rarely happens in a new edition. It is greatly to be hoped that they will maintain their enthusiasm for keeping this excellent text-book up to date. If at the same time they find it possible to continue the pruning process, so much the better ; future generations of medical, dental and science students will be the more grateful to them.

D. C. Harrison

\section{METEOROLOGY FOR GEOGRAPHERS}

Weather and Climate

By Dr. Clarence E. Koeppe and Dr. George C. de Long. Pp. viii +341 . (London: McGraw-Hill Publishing Company, Ltd., 1958.) $58 s$.

$\mathrm{T}$ HE authors of this book are American professors of geography. They state in the preface that it is intended primarily for students of geography needing a more detailed and scientific knowledge of weather and climate than is provided in a first geography course, but lacking the knowledge of physics and mathematics required for a standard course in technical meteorology, and for students interested in a liberal arts training without the intention of becoming professional geographers or meteorologists.

The first eleven chapters set out to give in 144 pages an outline of physical and dymamical meteorology without using any mathematies or assuming any knowledge of physics. This is a very difficult task in which the authors have not suceeeded. The sequence of ideas is loose, the essential physical principles are not stated or not clearly brought out, and in places the text would certainly be misleading or puzzling to readers of the type to whom it is directed. What, for example, is to be made of the following sentence about the relation of winds to the contours on the $500 \mathrm{mb}$. chart, "Winds tend to blow parallel with the contours and thus toward the depressions, which is in accord with the principle, already stated several times, that although air moves down the isobaric slope, it can move at a deflection of as much as 90 degrees to the slope" ?

The second part, of 190 pages, on climate is much better though not entirely free from error. The Earth's climates and corresponding types of vegetation are described in fair detail in terms of tho
Koppen-Geiger classification of them. An attractive feature is the photographs of typical landscapes in the various climatic types. Most illustrations, including cloud forms, are well reproduced, but what would the late G. A. Clarke of Aberdeen, Scotland, have said to the 'acknowledgments' (to the U.S. Weather Bureau) for the two of his photographs in Figs. 11-2 and 11-3 or the quality of reproduction of the first?

The book cannot on the whole be recommended. G. A. BULL

\section{ANIMAL MYCOSES}

Fungal Diseases of Animals

By Dr. G. C. Ainsworth and P. K. C. Austwick. (Review Series No. 6 of the Commonwealth Bureau of Animal Health.) Pp. xii $+148+12$ plates. (Farnham Royal : Commonwealth Agricultural Bureaux, 1959.) $20 s$.

CLINICAL mycology has never been a favourite 4 subject among pathologists. Lecturers promise to deal with it at the end of the course, time permitting; the hospital bacteriologist unwillingly allows a few mould cultures to lie at the end of the bench until one day, angered by the inexplicable appearance of a green flannel-jacket of Penicillium on some precious batch of media, he rises up and indignantly consigns them to the autoclave. Identifying and classifying moulds is a formidable enough task to account for much of the unpopularity of the subject; another cogent factor is the shortage of reference works. Conant's "Manual of Clinical Mycology", published in 1954, relieved the situation as regards fungal diseases of man, and Ainsworth and Austwick have now attempted to codify current knowledge of veterinary mycology. The literature is extremely well covered, and for this reason the book should be of great value to research workers and teachers; undergraduate students (for whom it is said to be partly intended) will probably find much of the detail confusing, and if too little space is devoted to clinical matters for the book to have any great appeal for the practitioner, this is perhaps understandable since neither author is a veterinarian.

It is the contrast between the general ætiological patterns of animal and human mycoses that medical workers and biologists will find most fascinating. The key to the problem seems to be the greater exposure of domestic animals to unhygienic con ditions, dirt, dust and spoiled or partly decomposing foodstuffs-in short, to infection with normally saprophytic fungi. Thus aspergillosis of chicks may follow inhalation of dust from mouldy grains or litter ; bovine mycotic abortion is associated with the winter feeding of spore-containing hay, mycotie mastitis with the feeding of stale brewers' grains and mould toxicoses with damaged maize and other cereals ; in sheep the multiplication of saprophytic Actinomycetes in rain-soaked and rotting wool leads to mycotic dermatitis, and soil or mud contamination of the limbs is a major factor in the rtiology of cattle farcy, a form of nocardiosis recalling in many ways Madura foot in the human subject. This is a theme which might well be elaborated in a later book, and who better than Dr. Ainsworth with his unique knowledge of both medical and veterinary mycology to do so?

T. E. SMITH 